Log Nr. 241

\title{
RADIONUCLIDE INVENTORIES FOR SHORT RUN-TIME \\ SPACE NUCLEAR REACTOR SYSTEMS \\ SAND92-2353C
}

Richard L. Coats

Sandia National Laboratories

SAND--92-2353C

P.O. Box 5800

Albuquerque, NM 87185

Phone: (505) 845-3218

\section{DISCLAIMER}

\section{Prepared for:}

Tenth Symposium on

Space Nuclear Power and Propulsion

Albuquerque, New Mexico

10-14 January 1993

final submission: 22 October 1992
This report was prepared as an account of work sponsored by an agency of the United States Government. Neither the United States Government nor any agency thereof, nor any of their employees, makes any warranty, express or implied, or assumes any legal liability or responsibility for the accuracy, completeness, or usefulness of any information, apparatus, product, or process disclosed, or represents that its use would not infringe privately owned rights. Reference herein to any specific commercial product, process, or service by trade name, trademark, manufacturer, or otherwise does not necessarily constitute or imply its endorsement, recommendation, or favoring by the United States Government or any agency thereof. The views and opinions of authors expressed herein do not necessarily state or reflect those of the United States Government or any agency thereof.
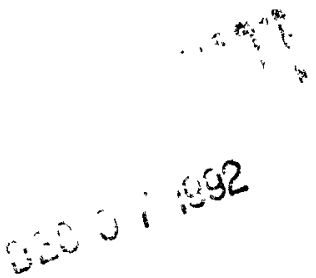

This work was performed at Sandia National Laboratories, which is operated for the U.S. Department of Energy under Contract DE-AC04-76DP00789. 


\section{DISCLAIMER}

This report was prepared as an account of work sponsored by an agency of the United States Government. Neither the United States Government nor any agency Thereof, nor any of their employees, makes any warranty, express or implied, or assumes any legal liability or responsibility for the accuracy, completeness, or usefulness of any information, apparatus, product, or process disclosed, or represents that its use would not infringe privately owned rights. Reference herein to any specific commercial product, process, or service by trade name, trademark, manufacturer, or otherwise does not necessarily constitute or imply its endorsement, recommendation, or favoring by the United States Government or any agency thereof. The views and opinions of authors expressed herein do not necessarily state or reflect those of the United States Government or any agency thereof. 


\section{DISCLAIMER}

Portions of this document may be illegible in electronic image products. Images are produced from the best available original document. 


\section{DISCLAIMER}

This report was prepared as an account of work sponsored by an agency of the United States Government. Neither the United States Government nor any agency Thereof, nor any of their employees, makes any warranty, express or implied, or assumes any legal liability or responsibility for the accuracy, completeness, or usefulness of any information, apparatus, product, or process disclosed, or represents that its use would not infringe privately owned rights. Reference herein to any specific commercial product, process, or service by trade name, trademark, manufacturer, or otherwise does not necessarily constitute or imply its endorsement, recommendation, or favoring by the United States Government or any agency thereof. The views and opinions of authors expressed herein do not necessarily state or reflect those of the United States Government or any agency thereof. 


\section{DISCLAIMER}

Portions of this document may be illegible in electronic image products. Images are produced from the best available original document. 
RADIONUCLIDE INVENTORIES FOR SHORT RUN-TIME SPACE NUCLEAR REACTOR SYSTEMS

\author{
Richard L. Coats \\ Sandia National Laboratories \\ P.O. Box 5800 \\ Albuquerque, NM 87185 \\ Phone: (505) 845-3218
}

\begin{abstract}
Space Nuclear Reactor Systems, especially those used for propulsion, of ten have expected operation run times much shorter than those for land-based nuclear power plants. This produces substantially different radionuclide inventories to be considered in the safety analyses of space nuclear systems. This presentation describes an analysis utilizing ORIGEN2 and DKPOWER to provide comparisons among representative land-based and space systems. These comparisons enable early, conceptual considerations of safety issues and features in the preliminary design phases of operational systems, test facilities, and operations by identifying differences between the requirements for space systems and the established practice for landbased power systems. Early indications are that separation distance is much more effective as a safety measure for space nuclear systems than for power reactors because greater decay of the radionuclide activity occurs during the time to transport the inventory a given distance. In addition, the inventories of long-lived actinides are very low for space reactor systems.
\end{abstract}

\title{
INTRODUCTION
}

The radionuclide inventory in a nuclear reactor system and related support system or facility at any given time consists of fission products, activation products, and actinides (and daughters) either originally present (the original fuel) or produced in operation.

The radiological risk afforded by an event in a given system containing radionuclides is the product of the radiological consequence of and the probability of occurrence of a given accident sequence summed over all credible accident scenarios. Although the evaluation of risk depends on many factors including safety features, such as system reliability, protect systems, physical containment or confinement, administrative controls, geographic location or isolation, and weather conditions, and on the physical characteristics (for example, stored energy) of the reactor system itself, a common factor in all components of radiological risk associated with radionuclides is the type and rate of radiation production from the radionuclide inventory at any given time.

The comparisons presented here will concentrate on one factor in consequence analysis, namely, the radionuclide inventory and the potential dose threat it poses. Other important factors, such as the specific radionuclide mix, the relative biological effectiveness of radiation from specific isotopes, the biological half-lives of specific nuclides, the physical characteristics such as aerosol form, the pathway vector (i.e., sky or cloudshine, groundshine, inhalation or ingestion), and the chemical and thermodynamic state, will not be considered in this comparison. The relative probability for release of radionuclides will, likewise, not be considered. 


\section{SYSTEMS TO BE COMPARED}

The systems to be compared were selected to represent a broad spectrum of potential radionuclide sources. A $1000-\mathrm{MWe}$ commercial nuclear power plant was chosen to represent a high fission burnup extreme of the potential radionuclide source spectrum, while a research pulse reactor was chosen to represent a reasonable lower bound. To represent space application systems, arbitrary, but reasonable assumptions were made as to the fuel inventory and the power histories resulting from test programs involving ground testing of a prototype engine and subassemblies of that engine. Each of the systems to be compared with regard to their radionuclide inventory is described below.

\section{0-MWe Power Plant}

The performance and fuel characteristics of Sequoyah Unit 2, a 3411-MWt pressurized water reactor (PWR), were selected to represent a 1000 -MWe commercial power plant. Sequoyah Unit 2 is initially fueled with $88.6 \times 10^{3} \mathrm{~kg}$ of uranium $\left(2.35 \%\right.$ enriched)in the form of $\mathrm{UO}_{2}$. Typical PWR fuel replacement schedules call for the replacement of approximately one-third of the fuel each year, resulting in an approximate two-year average core fuel age just prior to a fuel replacement shutdown. For this study, the power plant will be examined on the basis of a two-year, continuous 3411-MWt operation without fuel replacement.

Oxygen in the amount of $10.5 \times 10^{3} \mathrm{~kg}$ is assumed to be present in the fuel. Using typical PWR clad, $18 \times 10^{3} \mathrm{~kg}$ of zircaloy is estimated for the amount of cladding material present. Other structural materials, the coolant, and impurities (except cobalt) in all materials will be ignored in the calculation of activation product (non-actinide) radionuclide inventory.

\section{Ground Test Engine (GTE)}

The GTE is assumed to be a small compact assembly of fuel elements, and is assumed to operate for up to $2 \mathrm{TJ}$ of fission yield. For this study, a single, 1000-second, 2000-MW (2.0 $\mathrm{TJ}$ ) maximum operation will be assumed. The fuel will be assumed to be a mixture containing $28 \mathrm{~kg}$ of uranium enriched to $93 \%$. The other constituents of the mix are $\mathrm{Zr}$, steel, $\mathrm{C}$, $\mathrm{Al}$, and Be. Coolant and other structural materials will be ignored in estimating activation products.

\section{Sub-Assembly Test Package (STP)}

The STP is assumed to consist of a small number of GTE fuel elements to be tested up to 1.375 TJ for each fuel package examined. Because the dose potential is dominated by the contribution of the most recent operation, a single, maximum 500-s operation at $550 \mathrm{MW}(0.275$ TJ) will be assumed for this examination. The fuel package will be assumed to contain $7 \mathrm{~kg}$ of uranium enriched to $93 \%$ mixed with the same constituents as for GTE.

\section{$\underline{\text { ACRR }}$}

The Annular Core Research Reactor (ACRR) at Sandia National Laboratories is a research reactor that can be operated in either a super prompt critical pulse or a steady-state mode. It is 
fueled with $68 \mathrm{~kg}$ of uranium enriched to $35 \%$. The fuel form is $\mathrm{UO}_{2}-\mathrm{BeO}$, with $21.5 \%$ by weight $\mathrm{UO}_{2}$. A nominal pulse operation generates $300 \mathrm{MJ}$ of fission energy.

The system has been operated in the steady-state mode at $1 \mathrm{MW}$ for as long as two weeks in a single $(1.21 \mathrm{TJ})$ operation.

The fuel region can be treated as a mixture of fuel $\left(\mathrm{UO}_{2}-\mathrm{BeO}\right)$, holding cups $(\mathrm{Nb})$, and clad (304 stainless steel). The mass loadings assumed in this study are as given in the ACRR Safety Analysis Report. (Boldt et al., 1981.)

\section{ANALYSIS METHODS}

ORIGEN2 (Croff, 1983), developed for power plant application where fission run times are long, was used to calculate actinide and activation product activity and energy production rate as a function of time. Although ORIGEN2 was also used to calculate the corresponding values for fission products, it is significantly deficient in representing short-lived fission products and significantly underpredicts fission product energy production rates for short times after short duration operations.

Similar investigations of the adequacy of the ORIGEN2 representation for short-lived actinides and activation products have not been made.

DKPOWER, a fission product energy release code developed by Los Alamos National Laboratory (Wilson et al., 1984), was also used to calculate fission product activity and energy production rate because it is more accurate for short decay time. ANSI Standard (American Nuclear Society, 1979), CINDER (T. R. England et al., 1975), and ENDF/B-5 (LaBauve et al., 1981) data were used as input to DKPOWER. DKPOWER and ORIGEN2 give similar results for times $>1000$ seconds following an operation.

The calculations of activation product contributions are based on rough estimates for relative comparisons and pertain to the active core region only. Activation of pressure vessels, coolants, and other materials is ignored.

In all cases the respective inventories are examined on the basis of activity (curies) and energy production rate, the latter being more directly related to dose potential.

\section{CALCULATION RESULTS}

\section{Activation Products and Actinides}

In all cases investigated, the activation product activity was found to contribute less than one percent of the total activity.

It was found that the activation product gamma energy production rate from the STP radionuclide inventory is approximately $10 \%$ of that from the reference power plant core inventory immediately following operation. The GTE activation product activity would be approximately 3.6 times as much as for STP, or approximately $36 \%$ of that of the power plant. 
The GTE and STP activation product inventory activity decays much more rapidly, however, than that of a power plant, and after one hour of decay is 4 orders of magnitude less than the corresponding activation product activity of a power plant.

As can be seen from Figure 1, for short decay times, the actinide activity resulting from a nominal GTE operation is 4 orders of magnitude less than that resulting the reference power plant operation and, at late times ( $>2000$ hours), it is $>$ orders of magnitude less. Similarly, the actinide gamma energy production rate immediately following a GTE operation, is 4 orders of magnitude less than that of the reference power plant and 5 orders of magnitude less at late times. Actinides contribute less than $0.1 \%$ to the GTE radionuclide inventory.

Note also that while the actinide activity immediately following a GTE operation is much greater than that following an ACRR operation, the actinide activities are comparable at late times.

Thus, for estimates of potential external gamma dose rate from GTE or STP total core radionuclide inventories, actinides and activation products can, generally, be ignored. The same observations can be made for ACRR.

Even for the reference power plant, the fission products dominate for potential external dose considerations. The actinide photon energy production rate from the power plant inventory is at most only $20 \%$ of the total for decay times up to 50 hours and is even less for greater decay times. Activation products contribute $1 \%$ of the power plant core inventory gamma energy production.

For purposes of comparison the actinide activity of a 250 We plutonium-238 oxide radioisotope thermoelectric generator (RTG) is shown as a dashed line in Figure 1. It is noted that prior to operation, the GTE total activity is 5 orders of magnitude below that of the RTG. Immediately after a GTE operation, the GTE actinide activity exceeds that of a RTG, but falls to comparable values 1 hour later. At approximately 2000 hours following operation, the GTE actinide activity again is 5 orders of magnitude less than that of a RTG.

It is also interesting to note that the GTE fission product activity 1000 hours after operation is less than the RTG actinide activity.

\section{Fission Products}

As indicated previously, ORIGEN2 underpredicts fission product activity for early times following relatively short duration operations. Figure 2 illustrates this shortcoming. It is to be noted that for decay times greater than approximately 1000 seconds, the agreement between ORIGEN2 and DKPOWER is quite good. ORIGEN2 appears to overestimate the power plant fission product photon energy production rates by a factor of 2 over a wide range of decay times, but the agreement between DKPOWER and ORIGEN2 is quite good for short decay times.

The shortcoming of ORIGEN2 for early times following short duration operations is clearly evident. At six minutes of decay time, ORIGEN2 underpredicts fission product gamma energy 
production rates by factors of 3.0 and 3.8, respectively, for GTE and STP. The underprediction by ORIGEN2 can be as great as 2 orders of magnitude for short times following pulse operations of a pulse reactors such as ACRR.

Obviously, ORIGEN2 is not satisfactory for describing gamma activity during or immediately following GTE, STP, ACRR, or other short duration operations. For decay gamma activity during the power operation, even DKPOWER is deficient and one must fall back on experimental results such as the data of Maienschein et al., 1960; Peele et al., 1960; Walton, 1962; Sakharov et al., 1957; and Perkins, 1963 and 1958.

Figure 3 gives the total (gamma + beta) radiation energy production rate from fission products in each of the systems compared. It is noted that at very early times (30 seconds) after operation, the energy production rate from the GTE inventory is approximately $40 \%$ of that from the reference power plant inventory. The GTE inventory activity, however, decays rapidly with respect to that of the power plant and is only $5 \%$ as much one hour after the operation. For decay times as large as one day, the GTE inventory is still as much as $0.2 \%$ as potent as that of a large nuclear power plant. After eight years, the GTE fission product activity is only $10^{-5}$ as great as the corresponding power plant inventory. This result is consistent (within a factor of two) of that estimated on the basis of total fission product mass produced.

Although Figures 1, 2, and 3 are useful in comparing the dose rate potential offered by the various system fission product inventories, a better measure of dose potential is the integral of the energy release rate over time. Figure 4 gives the total energy released from the various system inventories as a function of time.

To illustrate the use of Figure 4, consider a person standing at some arbitrary distance from a GTE fission product inventory during the decay time interval of from 0 to 1 hour. The potential external gamma dose the individual could receive is approximately $10 \%$ of that he would receive had the equally shielded inventory been from a two-year continuous $3411-\mathrm{MW}$ operation of a nuclear power reactor (for example, at the end of a fuel cycle). The potential dose over the decay time interval of 0 to 24 hours would be approximately $2 \%$ of the potential dose offered by the power plant inventory. The 30-year potential dose would be only $0.03 \%$ that corresponding to the power plant inventory.

The distance of the site from the public has even greater impact for GTE or STP accident considerations than for power plant operations because of the much more rapid decay of the fission product inventory activity during the time to transport that inventory. Using Figure 4, it is found that $50 \%$ of the 30 -year GTE fission product dose potential is delivered within the first hour following operation (60\% in the first two hours), while only only $0.1 \%$ of the of the corresponding potential power plant dose is delivered in the first hour. Thus the delay time in inventory transport offers a greater reduction in space nuclear reactor dose potential than in a power plant dose potential.

Conversely, this observation emphasizes the relatively large on-site dose potential presented immediately after space nuclear reactor operations. 


\section{DISCUSSION}

Early decay time actinide activity in a space nuclear reactor system is a very small fraction $\left(10^{-4}\right)$ of that of a power plant. At late times ( $>1000$ hours), the fraction is even smaller $\left(10^{-7}\right)$ and is even comparable to that of ACRR.

The GTE actinide activity level is comparable to that of a RTG approximately 1 hour after operation, but falls rapidly to 5 orders of magnitude less than that of the RTG approximately 1000 hours after operation.

Early ( $<1 \mathrm{~min}$ ) and late ( $>8$ days) decay time GTE or STP inventory activation product gamma energy generation rate is approximately $10^{-1}$ and $10^{-6}$, respectively, of that corresponding to a commercial power plant.

The external dose potential of a space nuclear propulsion reactor system radionuclide inventory is dominated by the fission product component. The fission products generated in the last operation dominate over those generated in previous operations for decay times equal to or less than expected times between operations.

At early times following an operation, the space nuclear reactor fission product inventory activity is a substantial fraction of that of a large (3411-MW) commercial reactor near the end of a fuel cycle. The fission product activity (as well as the actinides and activation products activities), however, decreases rapidly (with time) to levels substantially less in a few hours.

For early times following operation, space nuclear propulsion reactor systems contain very large radionuclide inventories (dominated by fission products for external dose considerations) with high dose potential. Therefore, appropriate consideration in regard to this dose potential, must be given to (1) accident prevention and mitigation features, (2) confinement or containment features, (3) facility layout such as control bunker location, (4) shielding, (5) emergency response procedures, (6) facility/station and site personnel access and evacuation planning, and (7) general accident management. The on-site considerations (although less complex for the space nuclear test facility) should be at a depth comparable to the on-site considerations needed for a commercial power plant.

Site remoteness works even more favorably for short duration space nuclear testing than for power reactor operation because of the very rapid decay of the space nuclear reactor radionuclide source relative to the decay of a power reactor source during the time required to transport the inventories a given distance. As indicated, the 30-year potential dose from a GTE fission product inventory is reduced, through decay, by $50 \%$ in the first hour following operation. The corresponding dose potential from a power plant inventory is reduced by only $0.1 \%$ in the first hour.

\section{CONCLUSION}

Clearly, the particular characteristics of space nuclear radionuclide inventories are less threatening than and are different from those inventories (typical of power plants) that, traditionally, have been used in safety analysis. Hence, some deviation from the more 
traditional treatments is to be expected and is warranted in assessing relative risk and assuring safety of space nuclear systems.

\section{Acknowledgments}

This work was performed at Sandia National Laboratories, which is operated for the U.S. Department of Energy under Contract DE-AC04-76DP00789.

\section{References}

American Nuclear Society, "American National Standard for Decay Heat Power in Light Water Reactors," ANSA/ANS-5.1-1979, August 1979.

Boldt, K. R., et al. "Sandia Annular Core Research Reactor (ACRR) Safety Analysis Report," in SAND77-0208 Rev. November 1981, Sandia National Laboratories, Albuquerque, NM.

Croff, A. G., "ORIGEN2: A Versatile Computer Code for Calculating the Nuclide Compositions and Characteristics of Nuclear Materials," in Nuclear Technology 62, pp. 335351, September 1983.

England, T. R., R. Wilczynski, and N. L. Whittemore, "CINDER-10: An Interim Report for Users," LA-7620-MS, April 1975, Los Alamos National Laboratory, Los Alamos, NM.

LaBauve, R. J., T. R. England, D. C. George, "Integral Data Testing of ENDF/B Fission Product Data and Comparisons of ENDF/B with Other Fission Product Data Files," LA-9090MS (ENDF-320), November 1981, Los Alamos National Laboratory, Los Alamos, NM.

Maienschein, Peele, Zobel, and Love, "Proceedings of the 2nd International Conference Geneva," Vol. 15, p. 366 (1958); see also "Proceedings of International Conference on Pile Neutron Research in Physics," IAEA, Vienna, 1960; see also "Proceedings of Conference on Research Reactors in Physics," IAEA, Vienna, October 1960.

Peele, Maienschein, Zobel, and Love, $O R N L-3016$, p. 82, 1960, Oak Ridge National Laboratory, Oak Ridge, TN.

Perkins, J. F., "Decay of U235 Fission Products," U.S. Army Report RR-TR-63-11, July 1963; see also J. F. Perkins and R. W. King, Nucl. Science and Engineering, Vol. 3, pp. 726-746, 1958.

Sakharov, V. N., and A. I. Malofeev, Atomnaya Energiya, Vol. 10, p. 403, 1961; Soviet Atomic Energy (English Translation) Vol. 3, p. 1161, 1957.

Walton, R. B. (1962), General Atomics Report, GACD-3340.

Wilson, W. B., T. R. England, R. J. LaBauve, and D. C. George, "DKPOWR: A Code for Calculating Decay Power, Energy, Activity and $\beta+\gamma$ Spectra in LWR Fuel Using Fission Pulse Functions," LA-UR-85-15, December 1984, Los Alamos National Laboratory, Los Alamos, NM. 


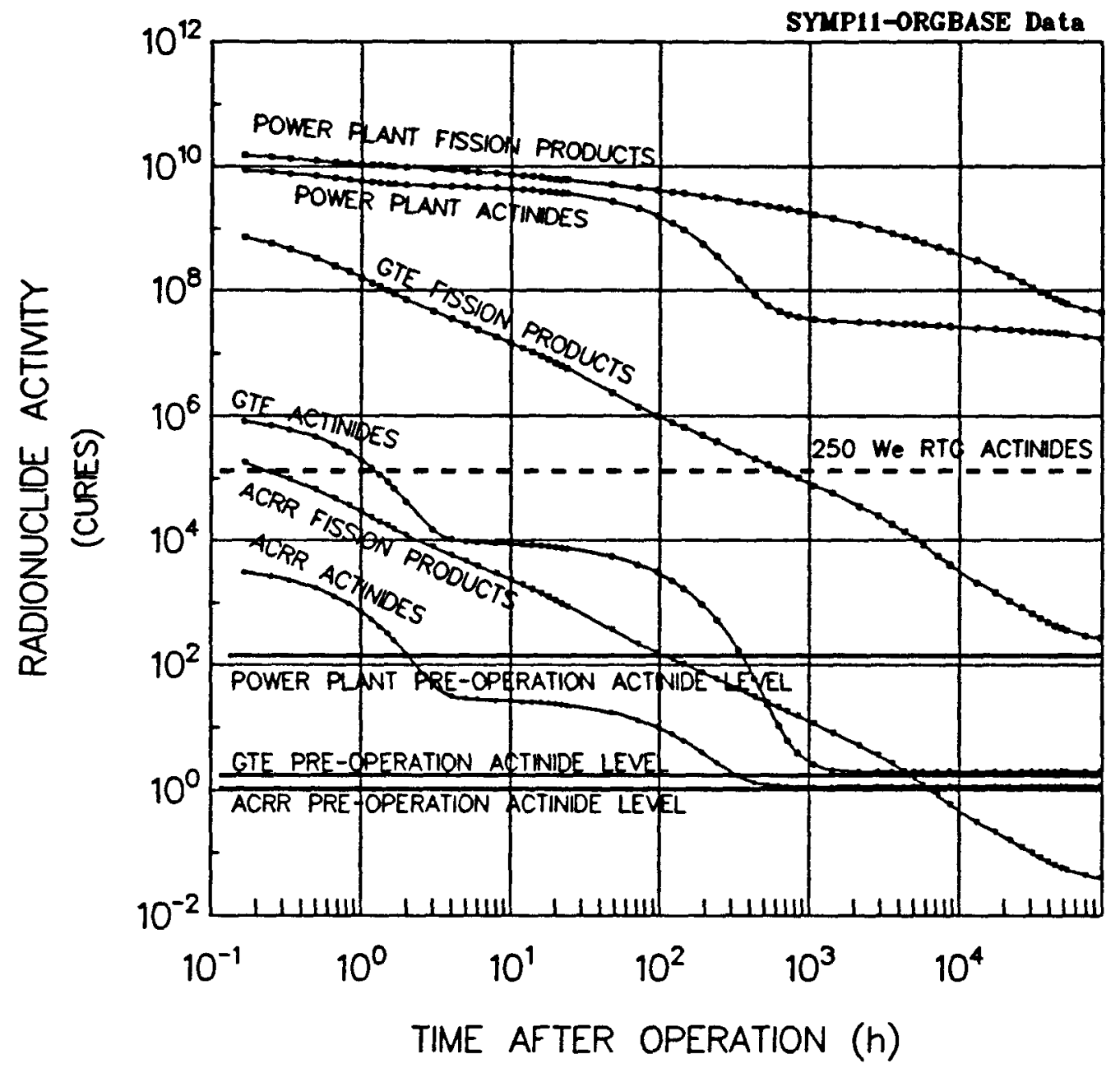

FIGURE 1. The Core Radionuclide Activity as a function of Time following a Continuous Two-Year 3411 MWt Reference Power Plant Operation, a Single, 1000-s, 2-GW Operation, and a Single 300-MJ ACRR Pulse Operation as calculated using ORIGEN2. 


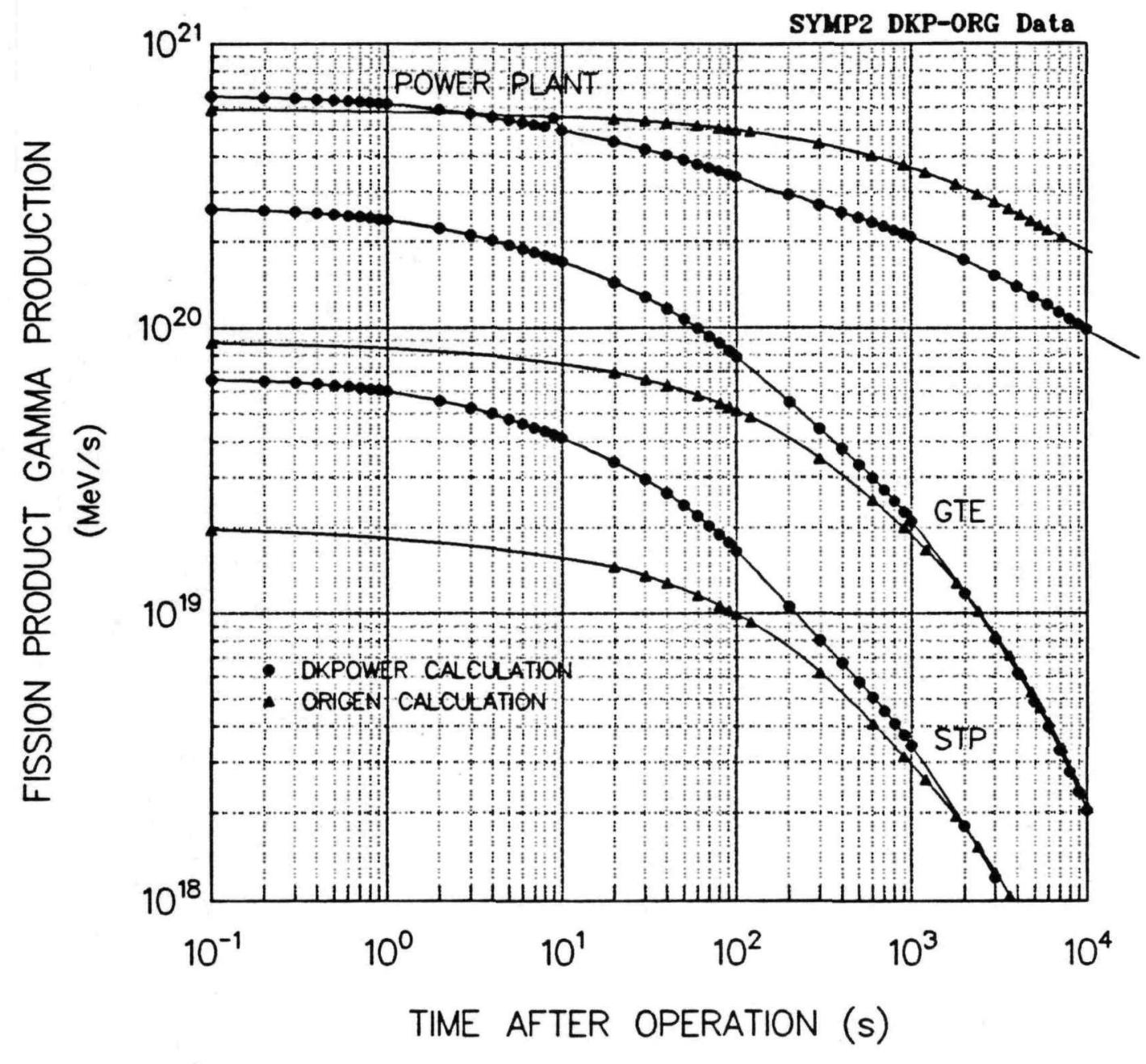

FIGURE 2. Comparison of the Time Dependent Core Fission Product Gamma Energy Production Rate following Single Operations of the Reference Power Plant, GTE, and STP as calculated using DKPOWER and ORIGEN2. 


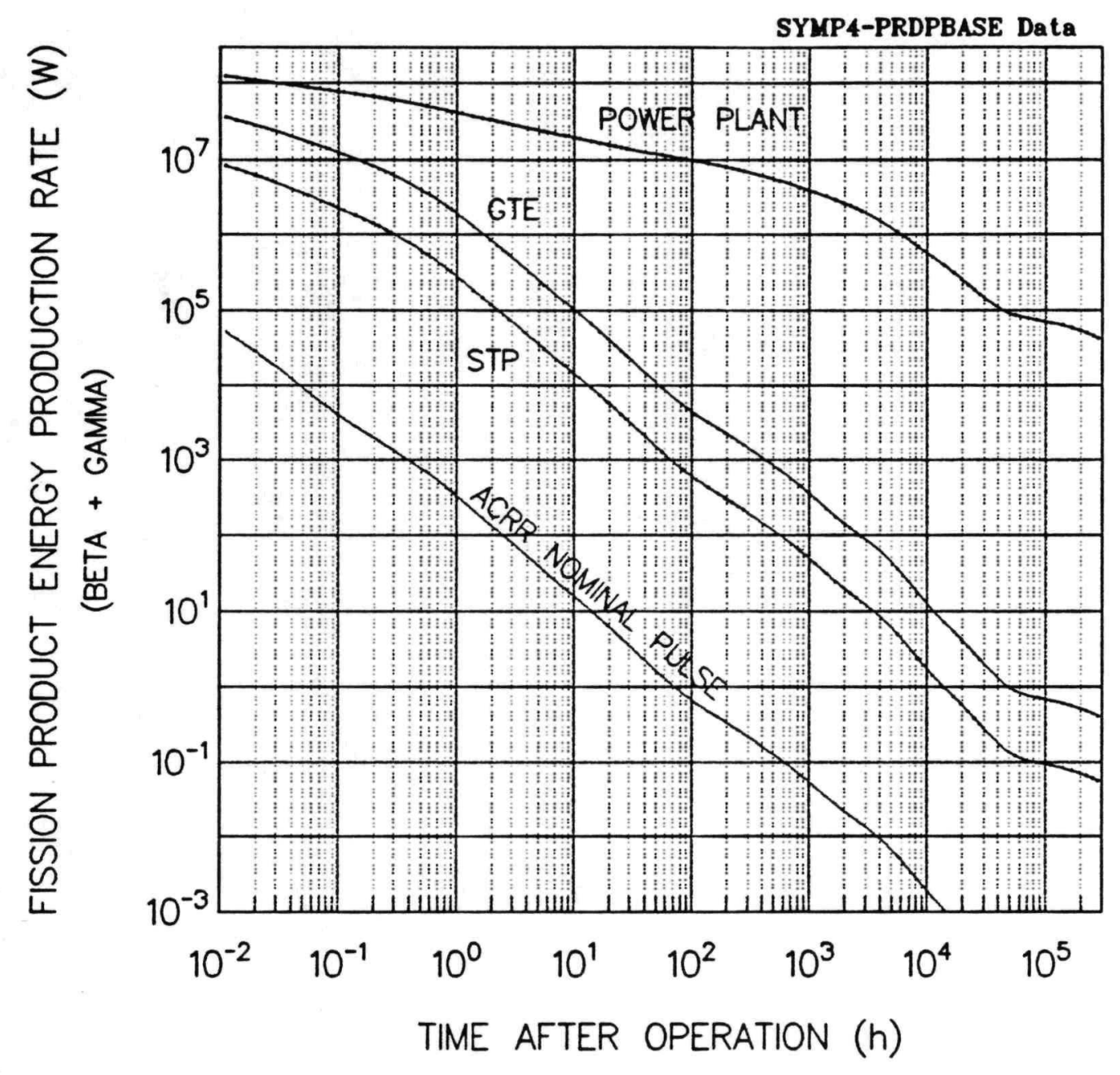

FIGURE 3. The Time Dependent Core Fission Product Energy Production Rate (Beta + Gamma ) following Single Operations of Various Systems as calculated using DKPOWER. 


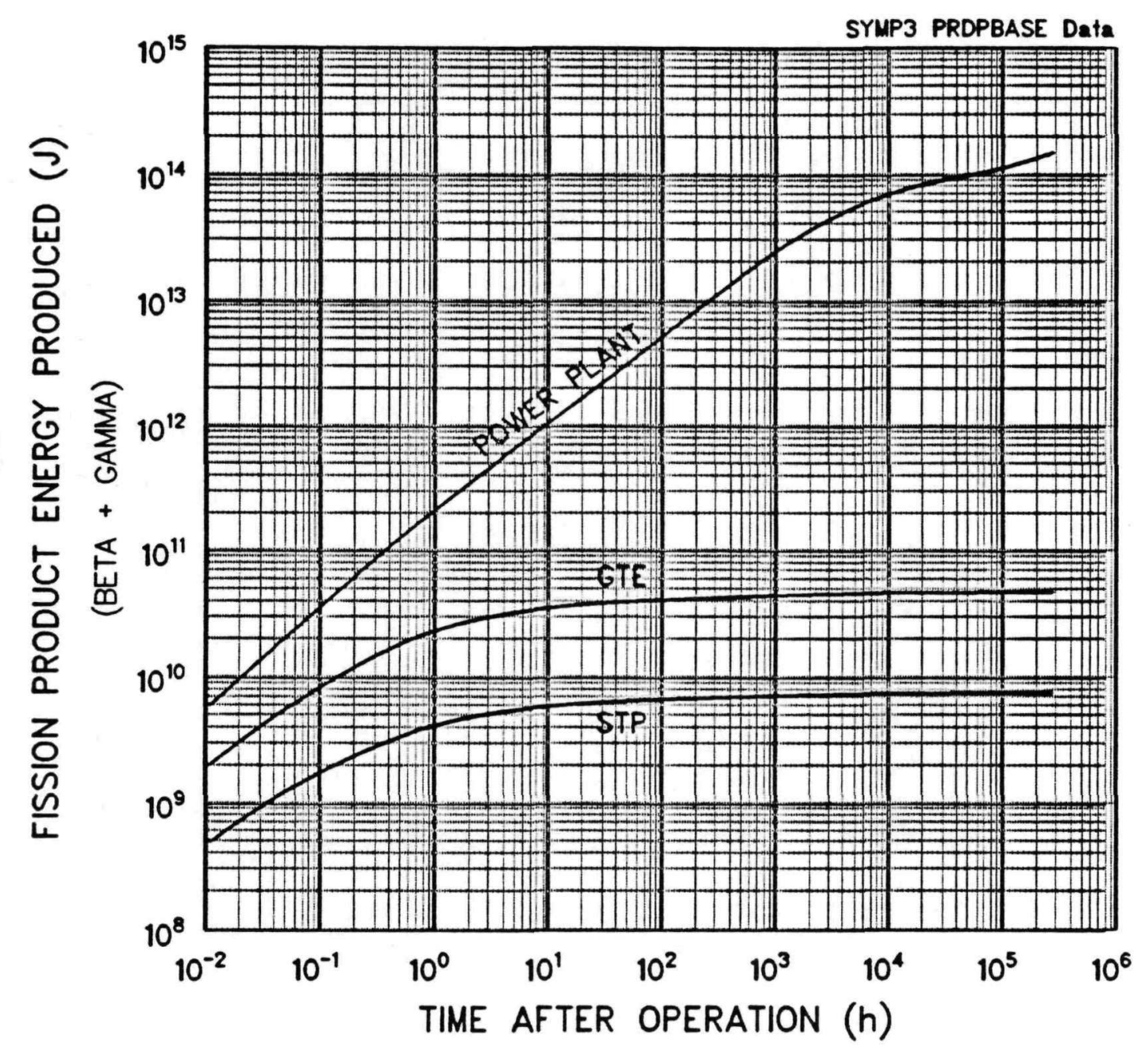

FIGURE 4. The Total Energy Released from the Fission Product Inventory following the Termination of the Operation (that is, the Time Integrated Fission Product Energy Release Rate) for Various Systems as calculated using DKPOWER. 